\title{
Research on magnetic seeding flocculation for arsenic removal by superconducting magnetic separation
}

\author{
Yiran Li, Jun Wang*, Ying Zhao, Zhaokun Luan

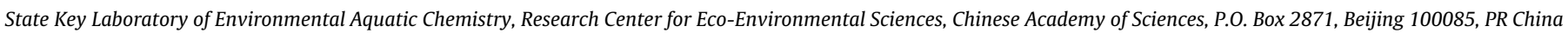

\section{A R T I C L E I N F O}

\section{Article history:}

Received 17 September 2009

Received in revised form 2 April 2010

Accepted 8 April 2010

\section{Keywords:}

Magnetic seeding flocculation

Arsenic removal

Superconducting magnetic separation

\begin{abstract}
A B S T R A C T
Arsenic removal was employed by combining the processes of magnetic seeding flocculation and open or high gradient superconducting magnetic separation (OGMS or HGMS). The effect of magnetic seeding flocculation on arsenic removal by OGMS or HGMS was systematically investigated. Magnetite $\left(\mathrm{Fe}_{3} \mathrm{O}_{4}\right)$ was used as magnetic seeding material and polymeric ferric sulfate (PFS) was added for combining the arsenic with the magnetite. The combination of PFS and magnetite was significant effect on arsenic removal. Magnetite or PFS dosages, magnetic seeding time and coagulant aids are the main factors in magnetic seeding process. In OGMS, arsenic removal efficiency increased from $72.5 \%$ to $90.9 \%$ when magnetite dosages increased from 25 to $300 \mathrm{mg} / \mathrm{l}$. After magnetic seeding time increased from 0 to $15 \mathrm{~min}$, arsenic removal efficiency increased from $80.0 \%$ to $94.5 \%, 84.5 \%$ to $97.1 \%$ or $87.0 \%$ to $98.7 \%$ after 50.75 , 72.5 or $108.75 \mathrm{mg} / \mathrm{l}$ PFS added, respectively. In HGMS, the application of cationic polyacrylamide (CPA) improved the arsenic removal capacity approximately $15 \%$ when certain arsenic removal efficiency was maintained. The grain size distribution, structure and zeta potential of flocs were studied to provide a complete picture of magnetic seeding flocculation process.
\end{abstract}

(C) 2010 Published by Elsevier B.V.

\section{Introduction}

Arsenic contamination in drinking water and groundwater has created serious health problems throughout the world. As a result, arsenic crisis has motivated researchers to develop various techniques for removing arsenic from water body. The conventional arsenic removal methods include adsorption [1], ion exchange, reverse osmosis, nanofiltration, coagulation (precipitation), membrane distillation [2], biological methods and photo catalytic oxidation, and so on.

Magnetic separation is a method for the separation of particles on the basis of their magnetic properties, however, it was proved that non-magnetic water pollutants could be removed with the combination of magnetic seeding techniques [3-5]. It has been shown that metal ions can be removed from liquids by means of hydroxide flocs [6,7] and these flocs combined with magnetic seeds can be separated from water body by means of magnetic separation. Magnetic seeding combined magnetic separation techniques were used for heavy-metal ions removal from waste water since the 1970 s $[5,8]$.

\footnotetext{
* Corresponding author. Tel.: +86 10 62849198; fax: +86 1062849198 . E-mail addresses: lyr2006xd@yahoo.com.cn (Y. Li), junwang@rcees.ac.cn (J. Wang)
}

The magnetic flocs with arsenic can be rapidly and efficiently removed by magnetic separation, even if the floc is very fine. This is because the strong magnetic force $\left(F_{\mathrm{m}}\right)$ acts on magnetic particles when they move through a magnetic field $(H)$ [6]:

$F_{\mathrm{m}}=V M(H) \frac{d H}{d x}$

where $V$ is the volume of the magnetic particle, and $M(H)$ is the magnetization of the magnetic particle in a magnetic field $(H)$. Consequently, magnetic particles are captured on a filter matrix by the magnetic tractive force $\left(F_{\mathrm{m}}\right)$ that overcomes other competing forces of gravitation, hydrodynamics and inertia or in an open gradient system, the magnetic tractive force combined gravitation can accelerate the flocs precipitation process.

Superconducting magnets have a number of advantages over resistive electromagnets in water treatment [5]. They can achieve an order of magnitude stronger field than ordinary ferromagneticcore electromagnets, which can be more efficient in separating flocculants combined magnetic seeds. Nowadays, the cost for producing superconducting magnets is considerable for industrial application. In the persistent state, the only power the magnet consumes is that needed for any refrigeration equipment to preserve the cryogenic temperature. Ferric coagulation/flocculation combined superconducting magnetic separation techniques became a promising application in arsenic removal in large area, unexpected arsenic leakage situation, and in addition in ground water arsenic treatment. 
Okada et al. investigated arsenic removal from geothermal water using iron(III) sulfate coagulation combined high gradient magnetic separation [9]. The system consists of a magnetic seeding process that adds extra magnetization to arsenic by chemical coagulation, and a reciprocal filter using a superconducting magnet that extracts magnetized arsenic from the geothermal water. However, the effects of magnetic seeding process on arsenic removal were not investigated.

In this paper, the effects of magnetic seeding flocculation on non-magnetic pollutants removal by OGMS or HGMS were first systematically studied. Magnetite or PFS dosages, magnetic seeding time and coagulant aids were investigated in the magnetic seeding process. Meanwhile, non-magnetic pollutants besides arsenic could also be purified from aqueous by magnetic seeding flocculation. The results are an attempt to optimize the magnetic seeding flocculation which will improve the non-magnetic pollutants removal efficiency by superconducting magnetic separation.

\section{2. Experimental}

\subsection{Materials and reagents}

All the reagents used were analytical grade and used as received. $\mathrm{Na}_{2} \mathrm{HAsO}_{4} \cdot 7 \mathrm{H}_{2} \mathrm{O}$ salt (Merck 6284) was dissolved in water for $50 \mathrm{mg} / \mathrm{l} \mathrm{As}(\mathrm{V})$ stock solution. These stock solutions were used to prepare experimental solutions of specified concentrations with tap water. The main cations and anions of the tap water are shown in Table 1:

The seeding material that has been used in this work was magnetite $\left(\mathrm{Fe}_{3} \mathrm{O}_{4}\right.$, analytical grade). Polymeric ferric sulfate(PFS) (effective Fe concentration of $11 \%$ ) was provided by Tianjin Dagang Oil Field Tianshui Water Purifying Agent Factory. The PFS was applied for magnetic seeding process before superconducting magnetic separation. The solutions of $\mathrm{KBH}_{4}$, thiourea, ascorbic acid were prepared by dissolving the adequate quantities of the compound in deionized water.

\subsection{Effects of PFS or magnetite on arsenic adsorption}

Arsenic water $(1000 \mathrm{ml})$ was prepared by using As(V) stock solution and tap water in mixing column, afterwards, a known weight of polymeric ferric sulfate (PFS) or PFS/Fe ${ }_{3} \mathrm{O}_{4}$ were added. The mixtures were mixed at $200 \mathrm{rpm}$ for $3 \mathrm{~min}$ (rapid mixing process), the suspension was filtered through $0.45 \mu \mathrm{m}$ PVDF membrane filter and filtrates were analyzed for arsenic concentration.

\subsection{Magnetic seeding flocculation process}

Simulated arsenic water was prepared using an automatic mixing machine, a known weight of flocculants and magnetite were added simultaneously. The mixture was stirred at $200 \mathrm{rpm}$ for $3 \mathrm{~min}$ (rapid mixing process) and followed by $70 \mathrm{rpm}$ for defined time (slow mixing process). The mixture was transferred to the settlement column and placed into the magnetic field immediately. The 1000 or $5000 \mathrm{ml}$ mixture was prepared for open or high gradient superconducting magnetic separation (OGMS or HGMS) respectively.

\subsection{Open/high gradient superconducting magnet separation}

Fig. 1 shows the magnetic field with different superconducting magnet operating currents at the top, middle, or bottom of the settlement column. The magnetic gradient was the source of the magnetic force $\left(F_{\mathrm{m}}\right)$ in OGMS or HGMS according to Eq. (1).

Magnetic separation process was carried out in a superconducting magnet (Institute of High Energy Physics, Chinese Academy of

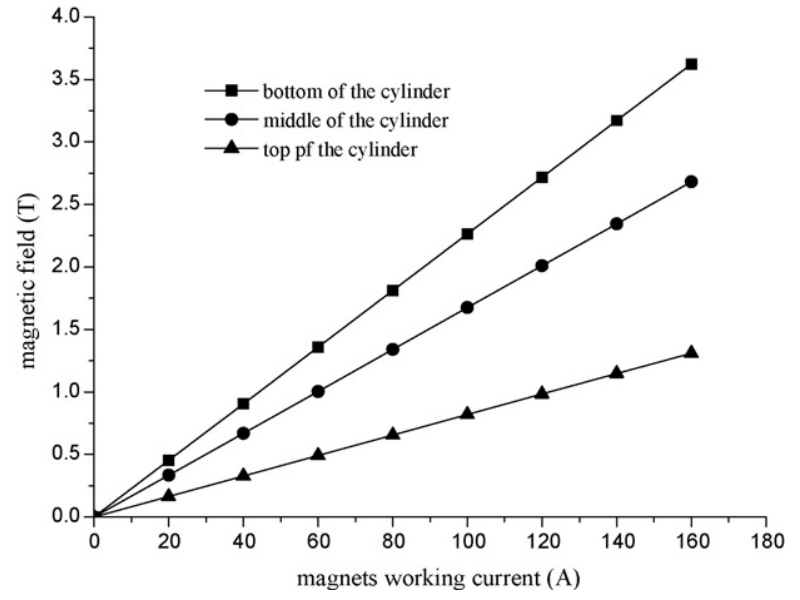

Fig. 1. Relationship between magnets working current and magnetic field.

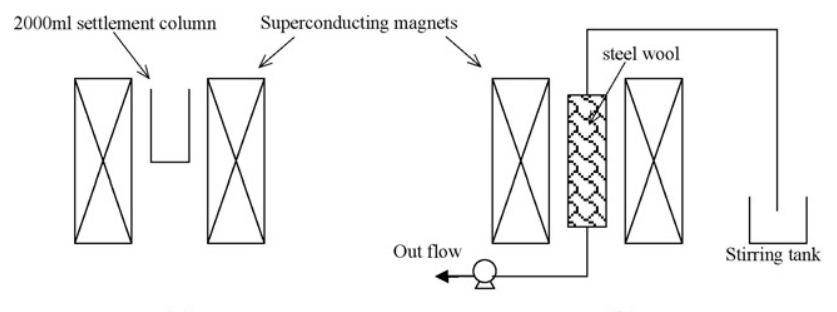

(a)

(b)

Fig. 2. Schematic explanation of magnetic separation equipment. Arrows show directions of arsenic water. (a) Static experiment for OGMS process (b) continuous flow for HGMS process.

Sciences, China) at various magnetic field strengths. A schematic diagram of magnetic separation equipment is illustrated in Fig. 2. In the OGMS, one $2000 \mathrm{ml}$ plastic column (with $40 \mathrm{~cm}$ height and $7.5 \mathrm{~cm}$ diameter) was placed in the gap between the magnetic poles (Fig. 2(a)). Samples were collected after defined time $\left(T_{\mathrm{S}}\right)$ by a plastic syringe connected with a copper tube at defined sampling site. Aqueous arsenic concentration was measured without any further treatment. In the HGMS (Fig. 2(b)), approximately $300 \mathrm{~g}$ stainless steel wool with a diameter of $50 \mu \mathrm{m}$ was filled in a plastic column (40 cm height, $7.5 \mathrm{~cm}$ diameter). The magnet working current was $160 \mathrm{~A}$ and the magnetic field was 3.62 T. Flow rate was measured and controlled by a fluid flowmeter. The outflow was collected after HGMS, and arsenic concentration was measured without any further treatment.

\subsection{Treatment capacity of magnetic separation}

The treatment capacity was measured by hydraulic retention time in OGMS and flow rate in HGMS. A settlement column with a diameter $(D)$ of $7.5 \mathrm{~cm}$ and a height $(H)$ of $40 \mathrm{~cm}$ was used. The treatment capacity of the certain column by OGMS process was measured by arsenic removal rate in different hydraulic retention times. Sampling time was converted to column's hydraulic retention time by the Eq. (2):

$T_{\mathrm{r}} H \pi\left(\frac{D}{2}\right)^{2}=T_{\mathrm{S}} L \pi\left(\frac{D}{2}\right)^{2}$

where $T_{\mathrm{r}}$ is the hydraulic retention time, $\min . T_{\mathrm{S}}$ is the sampling time, $\min$. $D$ is the diameter of the column, $\mathrm{cm}$. $H$ is the height of the column, $\mathrm{cm}$, and $L$ is the length from sampling point to the aqueous level, $\mathrm{cm}$. 
Table 1

Main cations and anions of the tap water $(\mathrm{mg} / \mathrm{l})$.

\begin{tabular}{|c|c|c|c|c|c|c|c|c|c|}
\hline $\mathrm{pH}$ & $\mathrm{HCO}_{3}{ }^{-}$ & $\mathrm{Cl}^{-}$ & $\mathrm{NO}_{3}{ }^{-}$ & $\mathrm{SO}_{4}^{2-}$ & $\mathrm{HPO}_{4}{ }^{2-}$ & $\mathrm{Mg}^{2+}$ & $\mathrm{Na}^{+}$ & $\mathrm{K}^{+}$ & $\mathrm{Ca}^{2+}$ \\
\hline 7.3 & 103.2 & 19.5 & 3.5 & 65.3 & $<0.01$ & 12.7 & 12.5 & 1.9 & 115.4 \\
\hline
\end{tabular}

\subsection{Analysis methods}

The Zeta potential analyzer (zetasizer 2000, Malvern Co., United Kingdom) was used to measure the zeta potential distribution, PFS was added in arsenic water for coagulation process. The time for one measurement was set to $1 \mathrm{~min}$ to record the zeta potential distribution and one sample was measured twice. The $\mathrm{pH}$ was measured at the same time with zeta potential measurement. Size distributions and mass structural information of magnetic flocs were determined using a Malvern Mastersizer 2000 (Malvern Co., United Kingdom), which ascertains size by analysis of forward scattered light. The suspension was measured by continuous recycle of water flowing through the sample cell of the instrument. A peristaltic pump with $5 \mathrm{~mm}$ internal diameter at a flow rate of $2.0 \mathrm{l} / \mathrm{h}$ was used to draw the suspension. The pump was located downstream of the instrument to prevent disturbing the flocs prior to measurement. The test solution was tap water containing $0.2 \mathrm{mg} / \mathrm{l} \mathrm{As}(\mathrm{V})$, the $\mathrm{pH}$ was not controlled artificially.

Arsenic was analyzed on atomic fluorescence spectrometer (AF-610A, Rayleigh Analytical Instrument Co., China). In order to ascertain the reproducibility of results, a group of experiments were repeated and the results were found to vary within $\pm 5 \%$. The experiments were performed in duplicate and the mean values were considered. The blank experiments showed no detectable arsenic or iron adsorbed on the walls of the flask.

\subsection{Fractal description of aggregate structure}

The theory of the mass fractal dimension using small-angle light scattering has been reported before [10-12]. This method was involves for measurement of light intensity $I$ as a function of the scatter vector $Q$. The vector is defined as the difference between the incident and scattered wave vectors of the radiation beam in the medium, which is given by [11]:

$Q=\frac{4 \pi n}{\lambda} \sin \left(\frac{\theta}{2}\right)$

where $n, \theta$, and $\lambda$ are the refractive index of the medium, the scattered angle, and the wavelength of radiation in vacuum, respectively. The mass fractal dimension $D_{\mathrm{f}}$ can be determined from the negative slope of a plot of log scatter intensity as a function of log scatter vector:

$I \propto Q^{-D_{\mathrm{f}}}$

\section{Results and discussion}

\subsection{Effect of PFS or magnetite on arsenic adsorption in non-magnetic condition}

Arsenic can be effectively adsorbed by iron oxide in a few minutes because $\mathrm{As}(\mathrm{V})$ is coordinated by ferric hydroxide sites before crystallite growth and coagulation processes [13]. The aqueous arsenic concentration was decreased from 0.2 to $0.024 \mathrm{mg} / \mathrm{l}$ or not detected after 14.5 or $61.6 \mathrm{mg} / \mathrm{l}$ PFS added, respectively (Fig. 3). The analytical grade $\mathrm{Fe}_{3} \mathrm{O}_{4}$ has no significant effects on arsenic absorption, the aqueous arsenic concentration remained about $0.024 \mathrm{mg} / \mathrm{l}$ after different dosages of $\mathrm{Fe}_{3} \mathrm{O}_{4}$ were added. The structure of analytical grade $\mathrm{Fe}_{3} \mathrm{O}_{4}$ may be different to natural magnetite in Gimenez's work [14], and which may also be different to mag-

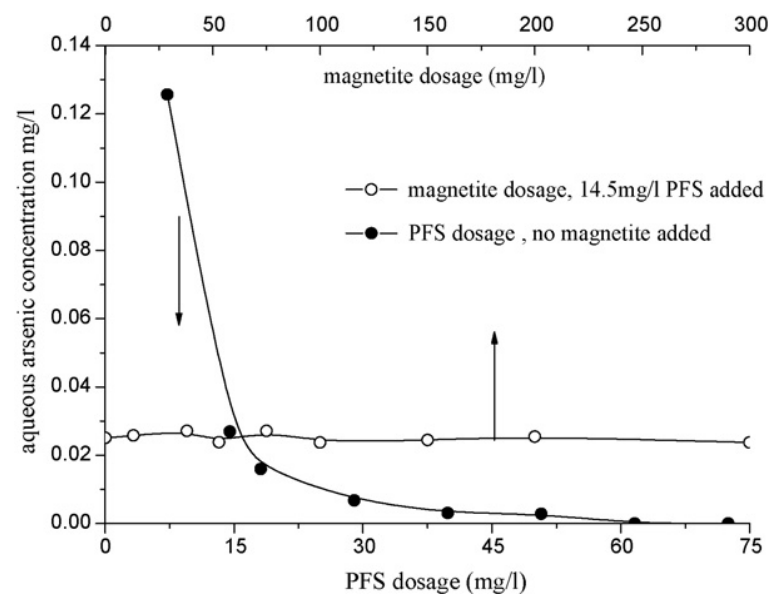

Fig. 3. Effects of PFS dosages and magnetite on arsenic adsorption.

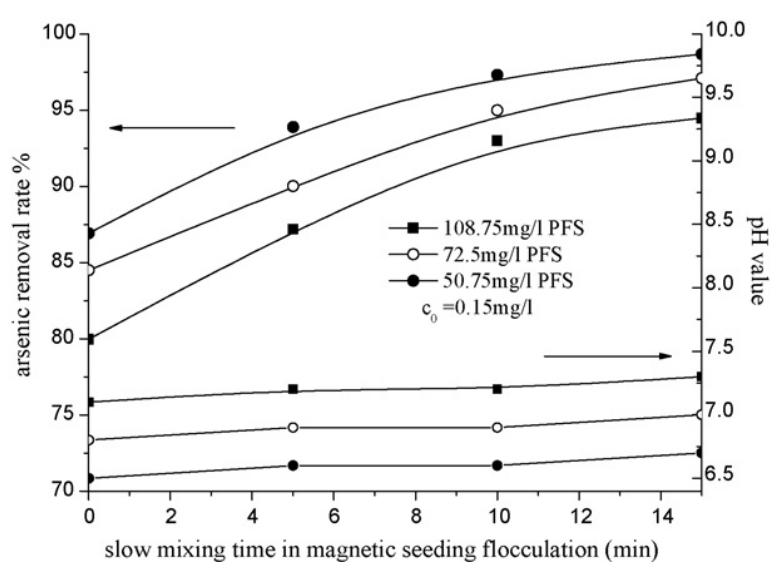

Fig. 4. Effects of flocculation time and PFS dosage on arsenic removal in OGMS treatment (100 mg/l magnetite dosage, magnets working current: $90 \mathrm{~A}, T_{\mathrm{r}}=24 \mathrm{~min}$ ).

netite nanoparticles in Mayo and Shen's work which were effective absorbent in heavy metal removal. [15,16]

Arsenic can be purified from aqueous in traditional wastewater treatment by two steps, (1) arsenic adsorbed by iron oxide in very short time and (2) iron oxide with $\mathrm{As}(\mathrm{V})$ separated from aqueous by coagulation and co-precipitation process. The step (2) costs lots of time and always needs large area of lands, thus leads to low arsenic treatment capacity. Superconducting magnetic separation treatment was investigated to replace the traditional step (2) in order to increase the aqueous arsenic treatment capacity.

\subsection{Effects of magnetic seeding time on arsenic removal}

The magnetic seeding process was influenced by the slow mixing process. Fig. 4 shows the effects of slow mixing $(70 \mathrm{rpm})$ process on arsenic removal in OGMS treatment. When $50.75,72.5$ or $108.75 \mathrm{mg} / \mathrm{l}$ FRS added, aqueous arsenic concentrations was 0.029 , 0.025 or $0.023 \mathrm{mg} / \mathrm{l}$ lowered respectively after $15 \mathrm{~min}$ slow stirred process.

The $\mathrm{pH}$ is one of the most important parameters controlling $\mathrm{As}(\mathrm{V})$ removal from water body. For pentavalent arsenic, the corresponding stable species and $\mathrm{pH}$ values are: $\mathrm{H}_{3} \mathrm{AsO}_{4}(\mathrm{pH} 0.0-2.0$ ), 


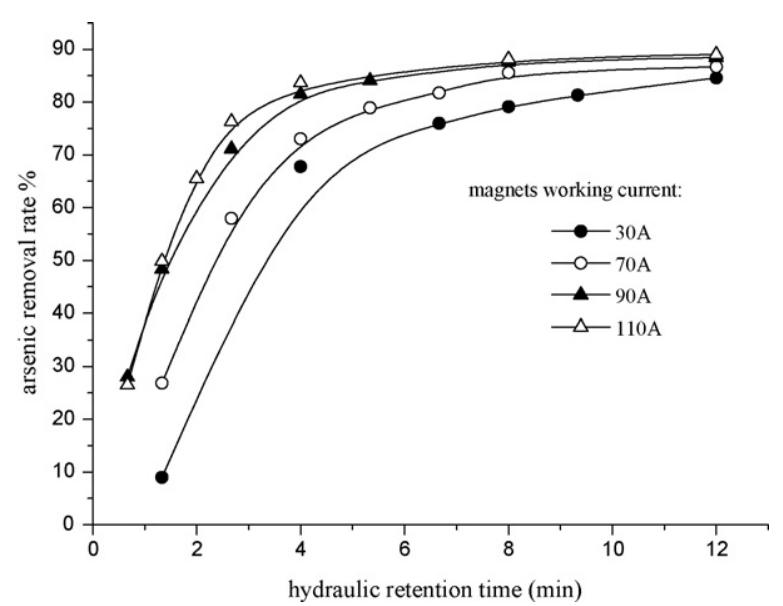

Fig. 5. The effects of magnetic field strength on arsenic removal in OGMS process, with 10 min slow mixing process, $75 \mathrm{mg} / \mathrm{l} \mathrm{PFS}$ and $100 \mathrm{mg} / \mathrm{l}$ magnetite added.

$\mathrm{H}_{2} \mathrm{AsO}_{4}{ }^{-}\left(\mathrm{pH}\right.$ 2.0-7.0), $\mathrm{HAsO}_{4}{ }^{2-}(\mathrm{pH} 7.0-12.0)$ and $\mathrm{AsO}_{4}{ }^{3-}(\mathrm{pH}$ 12.0-14.0) [17]. The $\mathrm{pH}$ was measured and the results were shown in Fig. 4. The $\mathrm{pH}$ did not change significantly during the $15 \mathrm{~min}$ slow mixing process. The stable species of $\mathrm{As}(\mathrm{V})$ when $\mathrm{pH}$ at 7.0 were $\mathrm{H}_{2} \mathrm{AsO}_{4}{ }^{-}$or $\mathrm{HAsO}_{4}{ }^{2-}$. The two types of arsenic were separated from aqueous and adsorbed in iron oxide (see Section 3.1) after more than $50 \mathrm{mg} / \mathrm{l}$ FRS added. Therefore, the detectable arsenic concentration was from iron oxide which was not settled with the magnetite.

\subsection{Effects of magnetic field strength on arsenic removal}

Fig. 5 shows the effects of magnetic field strength and hydraulic retention time on arsenic removal in OGMS. When hydraulic retention time was short (less than $12 \mathrm{~min}$ ), the magnetic field strength became an important factor for arsenic removal. The sampling site was $10 \mathrm{~cm}$ above the bottom of the settlement column and the hydraulic retention time $\left(T_{\mathrm{r}}\right)$ was calculated according to Eq. (2). The change of arsenic removal efficiency by hydraulic retention time can divided into two steps: (1) rapid increasing process in 0-4 min, and (2) slow increasing process in 4-12 min. The settlement velocity of magnetic flocs increased when magnet working currents (or the magnetic gradient see Fig. 1) improved. The arsenic removal efficiency was improved sharply when magnetic working current increased from 30 to $110 \mathrm{~A}$ in $0-4 \mathrm{~min}$. Most of magnetic flocs settled in $4 \mathrm{~min}$, after that, arsenic removal rate improved slightly (4-12 min). Most magnetic flocs were settled in $12 \mathrm{~min}$ when the magnet working current was $90 \mathrm{~A}$.

Fig. 6 shows that arsenic removal efficiency slightly decreased by magnetic gradient increased when hydraulic retention time was sufficient ( $24 \mathrm{~min}, 90 \mathrm{~A}$ ). In this experiment, $600 \mathrm{ml}$ mixtures were added in the settlement column with no slow mixing process, meanwhile, the sampling site was $2 \mathrm{~cm}$ under the aqueous level. Arsenic removal efficiency was $25.2 \%$ decreased when magnetic gradient increased from 0.4 to $1.3 \mathrm{~T}$. The reasons may be that iron oxide combined with magnetite was sheered by drag forces exerted by water and the gravitational forces. The faster settlement rate in strong magnetic gradient leads to more amount of iron oxide sheered of, therefore, lead to higher aqueous arsenic concentration.

\subsection{Effects of magnetite on arsenic removal in OGMS}

Fig. 7 shows the effects of magnetite on the removal efficiency in OGMS. The flocculants and magnetite were mixed at $200 \mathrm{rpm}$ for $3 \mathrm{~min}$ without slow mixing process. Arsenic removal efficiency increased to above $90 \%$ when dosage of magnetite was $300 \mathrm{mg} / \mathrm{l}$.

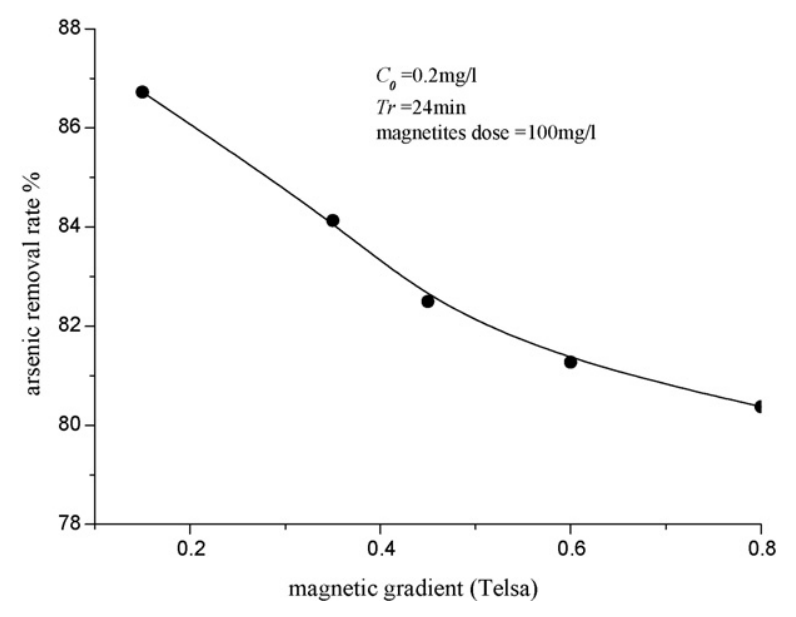

Fig. 6. Effects of magnetic gradient on arsenic removal in no slow stirring condition when hydraulic retention time was sufficient.

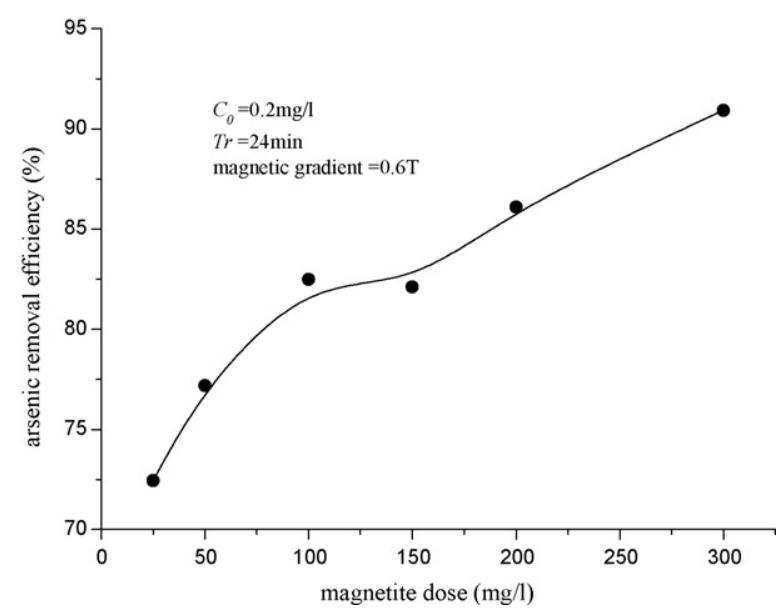

Fig. 7. The dependence of $\mathrm{As}(\mathrm{V})$ removal on an amount of magnetite $(\mathrm{pH}=7.0)$.

The $\mathrm{pH}$ was independent on magnetite which was stabilized at 6.8-7.0. Parts of iron oxides may not be firmly combined with magnetite, thus not settled in magnetic field. The amount of uncombined iron oxide decreased when more magnetite added. The reasons may be as follows: (1) the number of effective binding sites increased when magnetite increased. (2) The precipitation sweeping process of magnetite decreased the amount of iron oxide in aqueous.

\subsection{Effect of flow rate in HGMS on arsenic removal}

The flocculation time in magnetic seeding process before HGMS was 3 min rapid mixing process and 10 min slow mixing process. Flow rate was varied from 1.0 to $4.01 / \mathrm{min}$ for a solution containing $0.2 \mathrm{mg} / \mathrm{l}$ arsenic (Fig. 8). It was found that an increase in flow rate resulted in an increase in arsenic concentration. This experiments suggest that as the water through the canister increases, the drag force on the trapped magnetite floc particle becomes great enough to shear some of the iron oxide precipitates from the magnetite particles, resulting in lower quality product water [18]. This result was consistent to Fig. 8, it shows that the higher relative motion velocity between water and magnetic flocs, the more amounts of iron oxides been sheared of. After cationic polyacrylamide (CPA) added, arsenic removal capacity (flow rate) was $15 \%$ increased when certain arsenic removal efficiency was attained. It appears that CPA strengthened the combination between iron oxide and trapped 


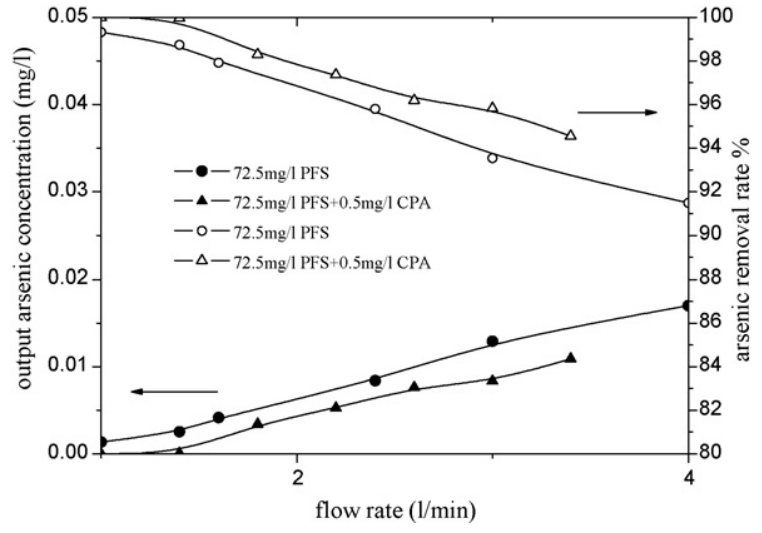

Fig. 8. HGMS treatment of arsenic solution in different flow rates $(100 \mathrm{mg} / \mathrm{l} \mathrm{mag-}$ netic).

Table 2

Factors and levels used in the $2^{3}$ factorial design study.

\begin{tabular}{lcc}
\hline Factor & Low level $(-1)$ & High level $(+1)$ \\
\hline Magnetite dosage, $\mathrm{mg} / \mathrm{l}(\mathrm{A})$ & 50 & 200 \\
CPA dosage, $\mathrm{mg} / \mathrm{l}(\mathrm{B})$ & 0 & 15 \\
Magnetic seeding time, $\min (\mathrm{C})$ & 0 & 1.25 \\
\hline
\end{tabular}

magnetite particles. It appears that the minimum magnetic field required for maximum removal is just that required to trap and hold the composite magnetite particles against the drag forces exerted by flowing water and the gravitational forces.

\subsection{Factorial design evaluation}

A $2^{3}$ full factorial design (three factors each, at two levels) was employed to evaluate the importance of magnetite, CPA dosage and magnetic seeding time. The response variable in is removal efficiency of arsenic. The factors were determined previously using one-variable-at-a-time experimental procedures. The matrix of three variables is varied at two levels $(+1,-1)$. The effects were designed as in Table 2 which shows the values of the factors selected in this study.

Arsenic removal efficiency $(Y)$ was measured for each of these tests as shown in Table 3. A first-order model was chosen to fit the experimental data:

$Y=b_{0}+b_{1} A+b_{2} B+b_{3} C$

where $Y=$ predicted response, $b_{1}=$ coefficients, $A=$ magnetite dosage, $\mathrm{mg} / \mathrm{l}, B=\mathrm{CPA}$ dosage, $\mathrm{mg} / \mathrm{l}$, and $C=$ magnetic seeding time, min. The statistical calculations ( $t$-test, $F$-test, analysis of variance (ANOVA) and multiple regressions) were performed using Microsoft Excel. Regression analysis was performed to fit the response function (arsenic removal efficiency) with the experimental data (Table 3).

Table 3

Experimental design matrix and results for the arsenic removal efficiency.

\begin{tabular}{lrrrr}
\hline Run number & \multicolumn{2}{l}{ Factor } & \multicolumn{2}{l}{$Y$} \\
\cline { 2 - 4 } & $A$ & $B$ & $C$ & \\
\hline 1 & -1 & -1 & -1 & 77.2 \\
2 & 1 & -1 & -1 & 86.1 \\
3 & -1 & 1 & -1 & 84.2 \\
4 & 1 & 1 & -1 & 89.5 \\
5 & -1 & -1 & 1 & 82.5 \\
6 & 1 & -1 & 1 & 91.3 \\
7 & -1 & 1 & 1 & 91.6 \\
8 & 1 & 1 & 1 & 95.5 \\
\hline
\end{tabular}

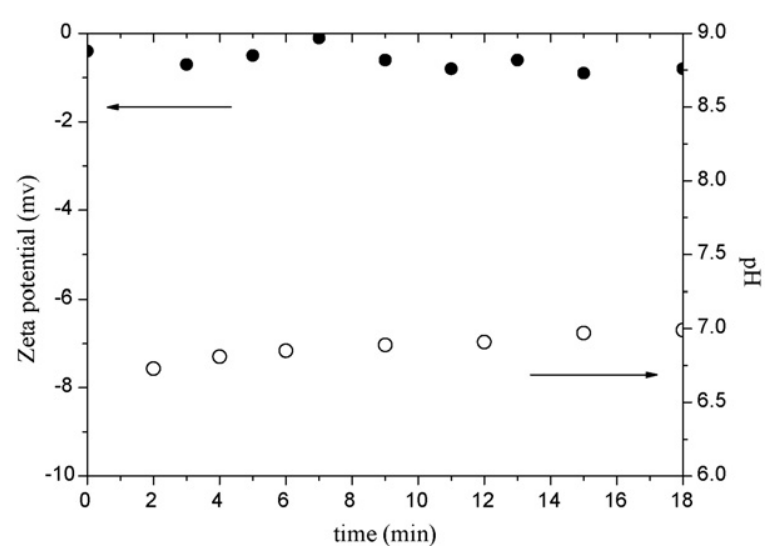

Fig. 9. Zeta potential of PFS absorbed arsenic and aqueous $\mathrm{pH}$ value during the stirring process.

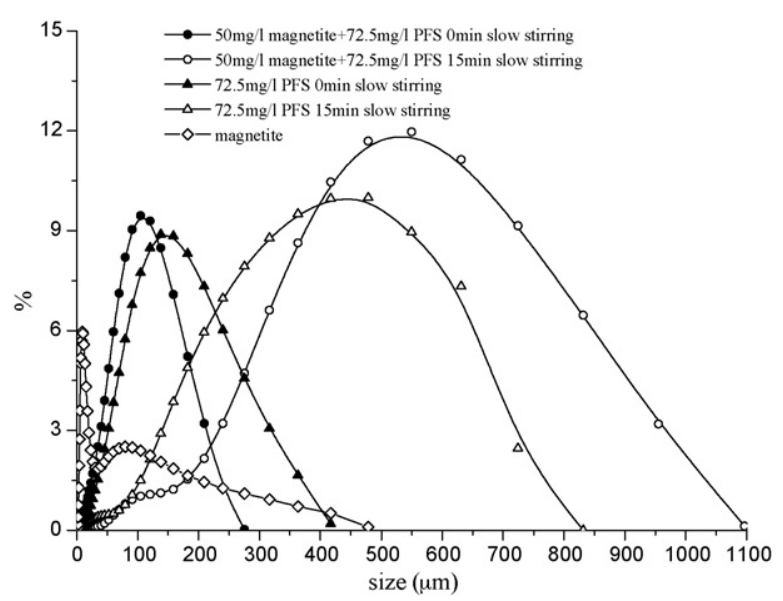

Fig. 10. Particle size distribution before or after slow stirring process.

The results calculated from the trial runs are incorporated in the regression Eq. (5) can be shown as:

$Y=87.25+3.125 A+2.875 B+3.250 C\left(R^{2}=0.97\right)$

This equation reveals the effect of individual variables on arsenic removal by superconducting magnetic separation (magnetic field $=5 \mathrm{~T}$ ). As seen from Eq. (6), magnetite and CPA dosages and magnetic seeding time have positive effect on arsenic removal. The greatest effect on arsenic removal was supplied by magnetic seeding time.

\subsection{Zeta potential and grain size analysis}

The investigation into the floc zeta potential showed that the zeta potential for PFS flocs after arsenic adsorption was independent on flocculation time (Fig. 9) and the results were consistent with Jiang and Graham [19]. For $72.5 \mathrm{mg} / \mathrm{l}$ doses, PFS colloids retained a net negative charge. In the pretreatment process, $\mathrm{pH}$ has no significant change (6.8-7.0 according to Fig. 9). The zeta potential of $\mathrm{Fe}_{3} \mathrm{O}_{4}$ was near $17 \mathrm{mV}$ when $\mathrm{pH}$ value was about 7.0 [6]. Therefore, CPA strengthened the combination between PFS and $\mathrm{Fe}_{3} \mathrm{O}_{4}$, and finally, increased the arsenic removal capacity in high gradient magnetic separation. The zeta potential of PFS and magnetite was not the reasons for the phenomenon which arsenic removal efficiency increased by the flocculation time in pretreatment.

Fig. 10 displays the development of particle size during the period of hydrolysis and flocculation from 0 to $18 \mathrm{~min}$ ( $3 \mathrm{~min}$ 


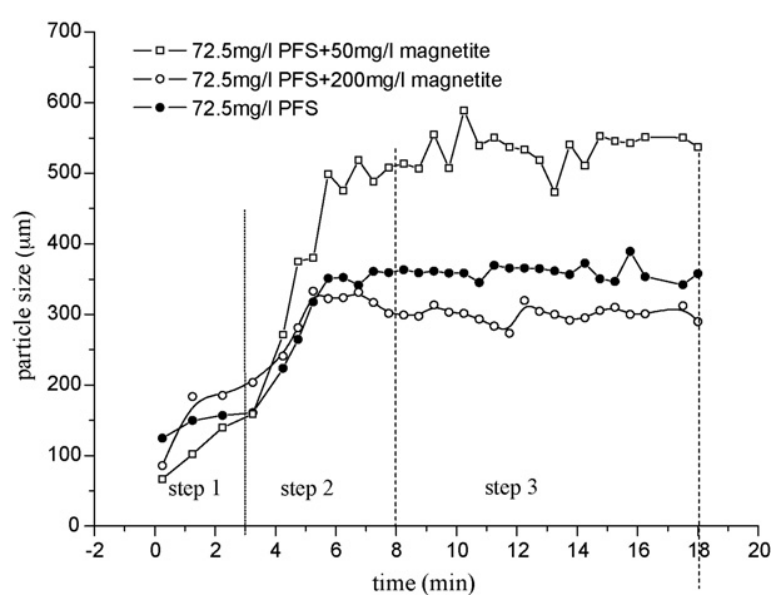

Fig. 11. Evolution of particle size after PFS and magnetite added.

fast mixing process followed by 15 min slow mixing). The size of microflocs formed by PFS and magnetite was quickly developed in fast mixing process ( $3 \mathrm{~min}, 200 \mathrm{rpm}$, step 1) and slowly developed in slow mixing process ( $3 \mathrm{~min}, 70 \mathrm{rpm}$, step 2), finally, the particle size was stabilized at $550 \pm 10 \mu \mathrm{m}$ (step 3). After magnetite added, the initial rate of flocculation was faster than that without magnetite added (during fast mixing process, step 1 ). The rate of flocculation was faster when more magnetite added. The total number of particles in the flocculation system was increased after magnetite added, thus enhanced the flocculation rate.

The distribution of magnetite was shown in Fig. 11. Average grain size $D(4,3)$ values of magnetite used in this work are about $52.244 \mu \mathrm{m}$. Meanwhile, there are more than $40 \%$ particles with grain size less than $30 \mu \mathrm{m}$. The distribution of grain size of PFS or $\mathrm{PFS} /$ magnetite particles at different times (during fast mixing step or after slow mixing step) was also shown in Fig. 11. The $D(4,3)$ of particles was slightly decreased (from 149.87 to $102.05 \mu \mathrm{m}$ ) after magnetite added during fast mixing. The small particles which was in the range of 5 to $180 \mu \mathrm{m}$ disappeared when magnetic seeds added, the reasons may be iron oxide combined with magnetite after mixing process. After 15 min slow mixing, the volume percentage of larger particles ranging from 550 to $830 \mu \mathrm{m}$ was $46.9 \%$ while this portion of particles was not detected without slow mixing. In the flocculation process, the mixing time may influence the capturing of particles in the mesh structure of iron oxide. The results may be one of the reasons for why slow mixing process strengthened the combination between iron oxide and magnetite.

\subsection{Floc structure determination}

Information about the magnetic seeding floc structures can be obtained by analyzing the data from static light scattering. The $\log -\log$ plot of $I$ against $Q$ for the flocs at different times is shown in Fig. 10, and the variation of $D_{\mathrm{f}}$ during the magnetic seeding flocculation is shown in Fig. 12. The mass fractal dimension $D_{\mathrm{f}}$ is restricted to the same range of $Q$ values in order to

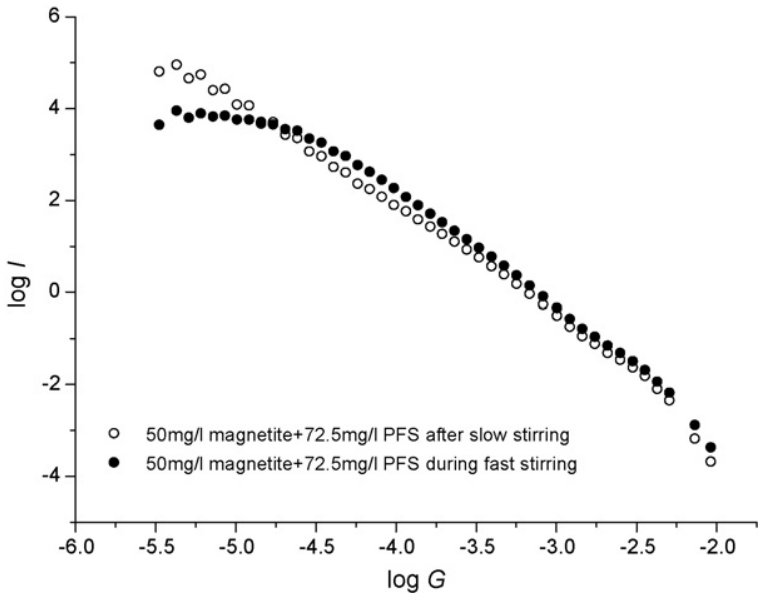

Fig. 12. The $\log -\log$ plot of $I$ as a function of $Q$ in the flocculation process.

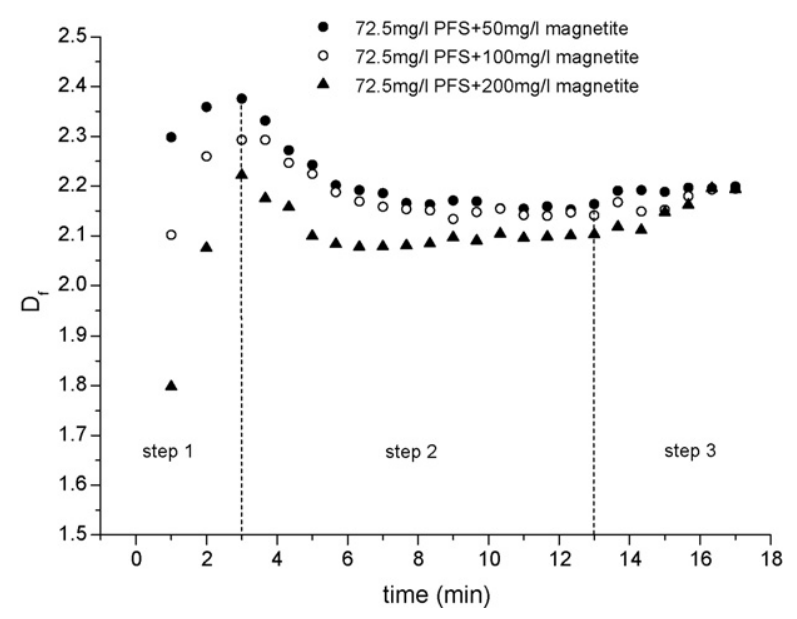

Fig. 13. Kinetics of fracture dimensions $\left(D_{\mathrm{f}}\right)$ during the flocculation process.

eliminate the polydispersity effect reported by other researchers [20,21].

As shown in Fig. 13, slight changes were apparently in the scattering dates of PFS-magnetite flocs in different flocculation times. $D_{\mathrm{f}}$ value was calculated in the $\log Q$ range of -4.46 to -3.41 according to Eq. (5), the $D_{f}$ values and $D(4,3)$ were shown in Table 4 . The variation of $D_{\mathrm{f}}$ value can be divided into three steps in magnetic seeding flocculation, shown in Fig. 13. During the fast mixing process (step 1 ), the $D_{\mathrm{f}}$ and $D(4,3)$ values both increased. However, based on the superconducting magnetic separation dates, the PFSmagnetite cannot be effectively separated in magnetic field without slow mixing. The $D_{\mathrm{f}}$ value was sharply decreased during $5 \mathrm{~min}$ in low mixing process (step 2 ), meanwhile, the $D(4,3)$ values significantly increased. The reasons should be sedimentation of flocs in the slow mixing. At the end of slow mixing process (step 3 ) the $D(4,3)$ values almost remained the same while the $D_{\mathrm{f}}$ value slightly

Table 4

Grain size and Fractal dimensions in different flocculation steps.

\begin{tabular}{|c|c|c|c|c|c|c|}
\hline & \multicolumn{2}{|c|}{ Step 1} & \multicolumn{2}{|c|}{ Step 2} & \multicolumn{2}{|c|}{ Step 3} \\
\hline & $D_{\mathrm{f}}$ & $D(4,3)$ & $D_{\mathrm{f}}$ & $D(4,3)$ & $D_{\mathrm{f}}$ & $D(4,3)$ \\
\hline $50 \mathrm{mg} / \mathrm{l}$ magnetite & 2.38 & 203.40 & 2.16 & 513.68 & 2.20 & 536.74 \\
\hline $100 \mathrm{mg} / \mathrm{l}$ magnetite & 2.29 & 189.34 & 2.14 & 417.45 & 2.20 & 425.50 \\
\hline $200 \mathrm{mg} / \mathrm{l}$ magnetite & 2.22 & 158.83 & 2.10 & 289.02 & 2.20 & 299.76 \\
\hline $1.25 \mathrm{mg} / \mathrm{lCPA}+100 \mathrm{mg} / \mathrm{l}$ magnetite & 2.26 & 193.56 & 2.20 & 425.32 & 2.18 & 449.53 \\
\hline $72.5 \mathrm{mg} / \mathrm{l}$ PFS only & 2.55 & 156.87 & 2.41 & 361.03 & 2.39 & 362.41 \\
\hline
\end{tabular}


increased. The interesting phenomena indicated that more compact PFS-magnetite flocs will be likely formed. It is partly possible that the large scale flocs are joined together to form more compact and stable structures due to restructuring and rearrangement. The compact and stable flocs formed at the end of slow mixing should contribute to the high superconducting magnetic separation efficiency. Meanwhile, $D_{\mathrm{f}}$ value was slightly decreased after CPA added, the reasons may be the floc structures by high molecular are more open in comparison with PFS.

Fig. 13 also showed that $D_{\mathrm{f}}$ value decreased after more magnetite added in step 1 and step 2. Meanwhile at the end of slow mixing process, the $D_{\mathrm{f}}$ value was independent to dosages of magnetite. However, superconducting magnetic separation efficiency of PFS-magnetite flocs increased by more magnetite added (Fig. 7). Therefore, the compact degree of flocs cannot totally characterize the combination of PFS and magnetite. For other mechanism explains, absorption of iron oxide on magnetite should play an important role in the magnetic seeding process. More magnetite leads to more active absorption site and more absorption time can lead to steady absorption, thus strengthened the combination between PFS and magnetite and finally increased arsenic removal efficiency.

\section{Conclusion}

The effect of magnetic seeding process on aqueous arsenic treatment by OGMS or HGMS was investigated. The main results are as follows:

(1) The arsenic solution was successfully treated by magnetic seeding process followed by OGMS or HGMS. Desirable treatment conditions of mixing time, quantity of above chemicals and magnetite were obtained. Methods of improving the arsenic treatment capacity in magnetic separation were also discussed.

(2) The amounts of magnetite, magnetic seeding time, and coagulant aids (cationic polyacrylamide) improved the arsenic treatment capacity in open/high magnetic separation. The combination conditions of non-magnetic particles and magnetite play an important role in magnetic separation process.

(3) The combination of arsenic, ferric oxide and magnetite was caused by the surface charge interaction, capture of particles in the mesh structure of iron oxide, and/or iron oxide precipitated on the magnetic particles.

\section{Acknowledgements}

Financial supports provided by the National High Technology R\&D Program (863) from Ministry of Science \& Technology of China (under grant no. 2008AA06A409-3), Public Industry Research for
National Environmental Protection (under grant no. 200709037), and the National Science and Technology Support Program of China (under grant no. 2006BAD01B02-02) are gratefully acknowledged.

\section{References}

[1] S.W. Zhang, C.J. Liu, Z.K. Luan, X.J. Peng, Arsenate removal from aqueous solutions using modified red mud, J. Hazard. Mater. 152 (2008) 486-492.

[2] D. Qu, J. Wang, D.Y. Hou, Experimental study of arsenic removal by direct contact membrane distillation, J. Hazard. Mater. 163 (2009) 874-879.

[3] N. Karapinar, Magnetic separation: an alternative method to the treatment of wastewater, Eur. J. Mineral. Process. Env. Prot. 3 (2003) 215-223.

[4] P. Anand, J.E. Etzel, F.J. Friedlsender, Heavy metals removal by high gradient magnetic separation, IEEE Trans. Magn. 21 (1985) 2062-2064.

[5] T. Ohara, H. Kumakura, H. Wada, Magnetic separation using superconducting magnets, Physica C 357-360 (2001) 1272-1280.

[6] Y. Terashima, H. Ozaki, M. Sekine, Removal of dissolved heavy metals by chemical coagulation magnetic seeding and high gradient magnetic filtration, Water Res. 20 (1986) 537-545.

[7] I.W. Nah, K.Y. Hwang, C. Jeon, H.B. Choi, Removal of Pb ion from water by magnetically modified zeolite, Miner. Eng. 19 (2006) 1452-1455.

[8] D. Feng, C. Aldrich, H. Tan, Removal of heavy metal ions by carrier magnetic separation of adsorptive particulates, Hydrometallurgy 56 (2000) 359368.

[9] H. Okada, Y. Kudo, H. Nakazawa, A. Chiba, K. Mitsuhashi, T. Ohara, Hitoshi Wada, Removal system of arsenic from geothermal water by high gradient magnetic separation-HGMS reciprocal filter, IEEE Trans. Appl. Supercon. 14 (2004) 1576-1579.

[10] J.F. Yu, D.S. Wang, X.P. Ge, M.Q. Yan, M. Yang, Flocculation of kaolin particles by two typical polyelectrolytes: A comparative study on the kinetics and floc structures, Colloids Surf. A: Physicochem. Eng. Aspects 290 (2006) 288-294.

[11] J. Guan, T.D. Waite, R. Amal, Rapid structure characterization of bacterial aggregates, Environ. Sci. Technol. 32 (1998) 3735-3742.

[12] G. Bushell, Y.D. Yan, D. Woodfield, J. Paper, R. Amal, On techniques for the measurement of the mass fractal dimension of aggregates, Adv. Colloid Interface Sci. 95 (2002) 1-50.

[13] S. Fendorf, M.J. Eick, P. Grossl, L. Donald Sparks, Arsenate and chromate retention mechanisms on goethite. 1. Surface structure, Environ. Sci. Technol. 31 (1997) 315-320.

[14] J. Gimenez, M. Martınez, J.D. Pablo, M. Rovira, L. Duro, Arsenic sorption onto natural hematite, magnetite, and goethite, J. Hazard. Mater. 141 (2007) 575-580.

[15] J.T. Mayo, C. Yavuz, S. Yean, L. Cong, H. Shipley, W. Yu, J. Falkner, A. Kan, M. Tomson, V.L. Colvin, The effect of nanocrystalline magnetite size on arsenic removal, Sci. Technol. Adv. Mater. 8 (2007) 71-75.

[16] Y.F. Shen, J. Tang, Z.H. Nie, Y.D. Wang, Y. Ren, L. Zuo, Preparation and application of magnetic $\mathrm{Fe}_{4} \mathrm{O}_{4}$ nanoparticles forwaste water purification, Sep. Purif. Technol. 68 (2009) 312-319.

[17] S.R. Wickramasinghe, B. Hana, J. Zimbronb, Z. Shenc, M.N. Karima, Arsenic removal by coagulation and filtration: comparison of groundwaters from the United States and Bangladesh, Desalination 169 (2004) 224-231.

[18] N. Karapinar, Magnetic separation of ferrihydrite from wastewater by magnetic seeding and high-gradient magnetic separation, Int. J. Miner. Process. 71 (2003) 45-54.

[19] J.Q. Jiang, N.J.D. Graham, Observations of the comparative hydrolysis/precipitation behaviour of polyferric sulphate and ferric sulphate, Water Res. 32 (1998) 930-935.

[20] J. Yu, D. Wang, X. Ge, M. Yan, M. Yang, Flocculation of kaolin particles by two typical polyelectrolytes: A comparative study on the kinetics and floc structures, Colloids and Surf. A: Physicochem. Eng. Aspects 290 (2006) 288-294.

[21] T.D. Waite, Measurement and implications of floc structure in water and wastewater treatment, Colloids Surf. A: Physicochem. Eng. Aspects 151 (1999) 27-41. 